\title{
DUAL-MODE MULTIFUNCTION FILTER REALIZED WITH A SINGLE VOLTAGE DIFFERENCING GAIN AMPLIFIER (VDGA)
}

\author{
Worapong Tangsrirat $^{1}$ - Tattaya Pukkalanun ${ }^{1}$ - Orapin Channumsin ${ }^{2 *}$
}

\begin{abstract}
${ }^{1}$ Department of Instrumentation and Control Engineering, Faculty of Engineering, King Mongkut's Institute of Technology Ladkrabang (KMITL), Bangkok 10520, Thailand

${ }^{2}$ Department of Electronics and Telecommunication Engineering, Faculty of Engineering, Rajamangala University of Technology Isan, Khonkaen Campus, Khonkaen 40000, Thailand
\end{abstract}

\begin{tabular}{|c|c|}
\hline ARTICLE INFO & Abstract: \\
\hline $\begin{array}{l}\text { Article history: } \\
\text { Received: } 03.04 .2019 . \\
\text { Received in revised form: } 06.06 .2019 . \\
\text { Accepted: } 09.06 .2019 .\end{array}$ & $\begin{array}{l}\text { This article presents the dual-mode multifunction biquad filter } \\
\text { realized employing only a single voltage differencing gain } \\
\text { amplifier (VDGA), one resistor and three capacitors. The } \\
\text { proposed filterwith one input and three outputs can configure as }\end{array}$ \\
\hline Keywords: & voltage-mode or current-mode filter circuit with the appropriate \\
\hline $\begin{array}{l}\text { Voltage Differencing Gain Amplifier } \\
\text { (VDGA) }\end{array}$ & $\begin{array}{l}\text { input injection choice. It can also synthesis the three standard filter } \\
\text { functions, which are highpass, bandpass, and lowpass responses }\end{array}$ \\
\hline Multifunction filter & without modifying the circuit configuration. Orthogonal \\
\hline Dual-mode operation & adjustment between the natural angular frequency $\left(\omega_{o}\right)$ and the \\
\hline Electronically tunable circuit & quality factor $(Q)$ of the filter is achieved. Detail analysis of non- \\
\hline Analog filter & ideal VDGA effects and circuit component sensitivity are included. \\
\hline DOI: https://doi.org/10.30765/er.1441 & $\begin{array}{l}\text { The circuit principle is verified by means of simulation results with } \\
\text { TSMC } 0.35-\mu m \text { CMOS process parameters. }\end{array}$ \\
\hline
\end{tabular}

\section{Introduction}

In the last decade, with growing interest in the design of analog signal processing and generating circuits, more attention is being paid to the design and synthesis of new electronically controllable active building blocks (ABBs), which are expected to perform better performance than voltage-feedback operational amplifier counterparts. In 2008, a set of modern electronic ABB were reviewed and introduced [1]. Among these, the most discussed $\mathrm{ABBs}$ have been contained the so-called voltage differencing unit (VDU), which is formed by the differential-input operational transconductance amplifier (OTA), in order to exhibit electronic tuning property. This results in emergence of numerous VDU-based ABBs, such as voltage differencing transconductance amplifier (VDTA) [2, 3], voltage differencing current conveyor (VDCC) [4], voltage differencing buffered amplifier (VDBA) [5, 6], and voltage differencing inverting buffered amplifier (VDIBA) [7-9].

In 2013, another ABB based on the voltage differencing unit so-called voltage differencing gain amplifier (VDGA) has been introduced to the analog domain [10]. This element is formed by a cascade connecting of the OTA with tunable gain voltage amplifier. When compared to the VDBA counterpart, the voltage buffer in its output section is replaced by the controllable-gain voltage amplifier, which makes VDGA-based circuits more flexible and useful for electronically tunable active circuit parameters. The VDGAs devices are not only suitable for current-mode signal processing, but also provide certain important advantages in voltage-mode processing circuits. It has also been observed that the VDGAs find widespread applications especially in the areas of analog signal processing and active circuit implementation ranging from amplifiers, universal filters, sinusoidal oscillators and impedance simulator circuits [11-16]. By introducing VDGAs in sinusoidal oscillator design, new more profitable topologies are available in literature [11-13]. In [14-16], a number of VDGAbased filter structures has been reported. The filter of [14] employs one VDGA, one floating capacitor and one

\footnotetext{
* Corresponding author

E-mail address: o.channumsin.rmuti@gmail.com
} 
grounded resistor to realize only first-order voltage-mode allpass characteristic with electronically tunable property. Also, the $\mathrm{n}^{\text {th }}$-order transfer function synthesizers reported in [15] can realize only lowpass voltage responses. As reported in [16], the authors presented an electronically tunable dual-mode multifunction filter with one input and three output terminals using VDGAs, which can perform either voltage-mode filter or current-mode filter from the same configuration. However, it contains two VDGAs and three external passive capacitors.

Although there are various configurations to realize universal biquadratic filters employing different contemporary active components developed in the technical literature [17-27], the works of [17-22] operated in the voltage-mode, while the remaining ones in [23-27] operated in the current-mode. Moreover, the filter structures reported in [17-21], [23-26] also require at least two active components for their realizations. Despite the extensive work on analog active filters, there is still a requirement to develop novel filter configurations, which provide more advantages than the existing configurations, for example in terms of implementation and operational flexibility. Consequently, the versatile universal active filter, which can operate in both voltage-mode and current-mode namely dual-mode filter, seems to be more flexible and universality for several communication systems and signal processing applications and solutions. In addition to low power dissipation and manufacturing cost, it is important to keep the active component count at minimum.

Considering this fact, the main objective is to propose the single-input three-output (SITO) multifunction frequency filter realized with a single VDGA as a fundamental active element, and four passive elements. With the appropriate selection of the input signal excitation, the proposed frequency filter can provide either voltage or current signal outputs. The proposed SITO-type configuration provides realizing highpass (HP), bandpass (BP) and lowpass (LP) filters simultaneously without the component matching constraints. The orthogonal adjustment of the natural angular frequency $\left(\omega_{o}\right)$ and the quality factor $(Q)$ can be obtained from the structure. The proposed idea is verified by the simulation results with a CMOS $0.35-\mu \mathrm{m}$ process technology from TSMC.

\section{VDGA fundamental}

An ideal VDGA has a pair of infinite-impedance input voltages $v_{p}$ and $v_{n}$, two infinite-impedance output currents $i_{z}$ and $i_{x}$, and a zero-impedance output voltage $v_{w}$. Hence, the terminal characteristics of the VDGA illustrated symbolically in Figure 1 can be defined by the following matrix expression:

$$
\left[\begin{array}{l}
i_{p} \\
i_{n} \\
i_{z} \\
i_{x} \\
v_{w}
\end{array}\right]=\left[\begin{array}{cccc}
0 & 0 & 0 & 0 \\
0 & 0 & 0 & 0 \\
g_{m A} & -g_{m A} & 0 & 0 \\
0 & 0 & g_{m B} & 0 \\
0 & 0 & \beta & 0
\end{array}\right]\left[\begin{array}{l}
v_{p} \\
v_{n} \\
v_{z} \\
v_{x}
\end{array}\right]
$$

where $g_{m A}, g_{m B}$ and $\beta$ are the transconductance gains and the voltage gain of the VDGA, respectively.

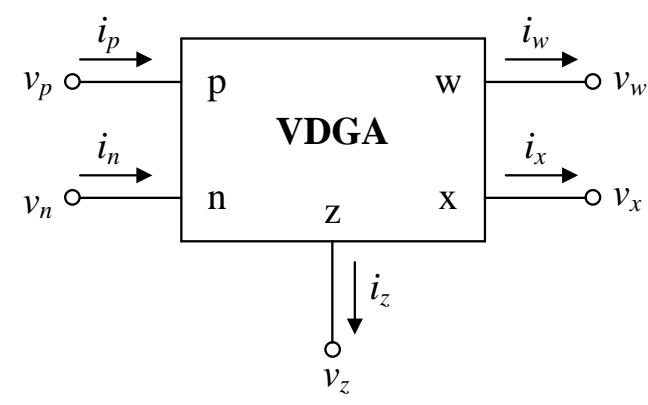

Figure 1. Schematic symbol of the VDGA.

In Figure 2, the possible CMOS implementation of the VDGA consisting of three tunable transconductors $\left(\mathrm{M}_{1 \mathrm{~A}}-\mathrm{M}_{9 \mathrm{~A}}, \mathrm{M}_{1 \mathrm{~B}}-\mathrm{M}_{9 \mathrm{~B}}\right.$ and $\left.\mathrm{M}_{1 \mathrm{C}}-\mathrm{M}_{9 \mathrm{C}}\right)$ is given, where each of them realizes an independent transconductances 
$g_{m A}, g_{m B}$, and $g_{m C}$, respectively $[10,11]$. In the internal circuit structure of Figure 2, the transistor sizes (W/L in $\mu \mathrm{m} / \mu \mathrm{m})$ are listed in Table 1 . The value of $g_{m k}(k=A, B, C)$ can be approximately determined by the following relation [28]:

$$
g_{m k}=\left(\frac{g_{m 1 k} g_{m 2 k}}{g_{m 1 k}+g_{m 2 k}}\right)+\left(\frac{g_{m 3 k} g_{m 4 k}}{g_{m 3 k}+g_{m 4 k}}\right)
$$

and

$$
g_{m i k}=\sqrt{K I_{B k}}
$$

and $\quad K=\frac{\mu C_{o x} W_{i}}{2 L_{i}} \quad(i=1,2,3,4)$, and $I_{B k}$ is the external biasing current, $\mu$ is the free carrier mobility in the channel, $C_{o x}$ is the gate capacitance per unit area of the gate oxide, $W_{i}$ and $L_{i}$ are the channel width and length, of the $i$-th transistor, respectively.

From Figure 2, the differential input voltage $\left(v_{p}-v_{n}\right)$ is converted into the current $i_{z}$ at the z-terminal with transconductance gain $g_{m A}$ by the transconductor $\mathrm{M}_{1 \mathrm{~A}}-\mathrm{M}_{9 \mathrm{~A}}$ or $i_{z}=g_{m A}\left(v_{p}-v_{n}\right)$. Also, the transconductor $\mathrm{M}_{1 \mathrm{~B}^{-}}$ $\mathrm{M}_{9 \mathrm{~B}}$ will convert the corresponding voltage $v_{z}$ to the output current $i_{x}$ by the transconductance $g_{m B}$ or $i_{x}=g_{m B} v_{z}$. By connecting a pair of independent tunable transconductors $\mathrm{M}_{1 \mathrm{~B}}-\mathrm{M}_{9 \mathrm{~B}}$ and $\mathrm{M}_{1 \mathrm{C}}-\mathrm{M}_{9 \mathrm{C}}$, a current-controlled voltage amplifier can be realized with the voltage amplifying action $\left(v_{w}=\beta v_{z}\right)$ or

$$
\beta=\frac{v_{w}}{v_{z}}=\frac{g_{m B}}{g_{m C}}
$$

According to eqs. (2) and (3), the VDGA device has electronic adjusting capability of its important parameters $g_{m A}, g_{m B}$ and $g_{m C}$ by means of external bias currents $I_{B A}, I_{B B}$ and $I_{B C}$, respectively.

Table 1. Transistor sizes of CMOS VDGA in Figure 2.

\begin{tabular}{|c|c|}
\hline Transistors & $\mathrm{W} / \mathrm{L}(\mu \mathrm{m} / \mu \mathrm{m})$ \\
\hline $\mathrm{M}_{1 k}-\mathrm{M}_{2 k}$ & $16 / 0.7$ \\
\hline $\mathrm{M}_{3 k}-\mathrm{M}_{4 k}$ & $28 / 0.7$ \\
\hline $\mathrm{M}_{5 k}$ & $7 / 0 / 7$ \\
\hline $\mathrm{M}_{6 k}-\mathrm{M}_{7 k}$ & $8 / 0 / 7$ \\
\hline $\mathrm{M}_{8 k}-\mathrm{M}_{9 k}$ & $21 / 0.7$ \\
\hline
\end{tabular}

\section{Proposed dual-mode multifunction filter configuration}

The proposed dual-mode multifunction filter, based on and using single VDGA is shown in Figure 3. Two grounded capacitors $\left(C_{2}\right.$ and $\left.C_{3}\right)$, one floating capacitor $\left(C_{1}\right)$ and one floating resistor $\left(R_{1}\right)$ are employed in the design. The employment of grounded capacitors is particularly advantageous for integration point of view [29]. Although the capacitor $C_{1}$ is floating for the voltage-mode operation, it can be realized even in recent integrated circuit technology of a decade ago with a CMOS process, which provides a second poly layer [30]. Also, note that the resistor $R_{1}$ can be replaced simply by an electronic resistor using the MOS transistors [31]. 


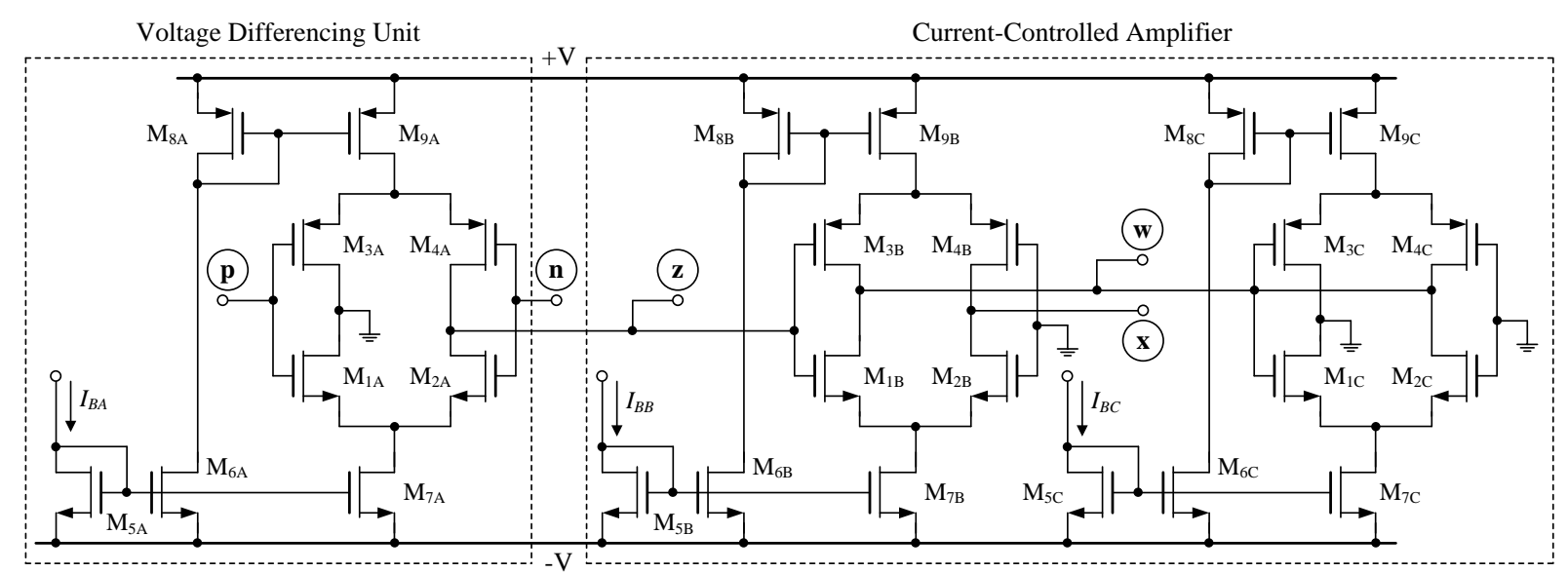

Figure 2. CMOS VDGA used in this work.

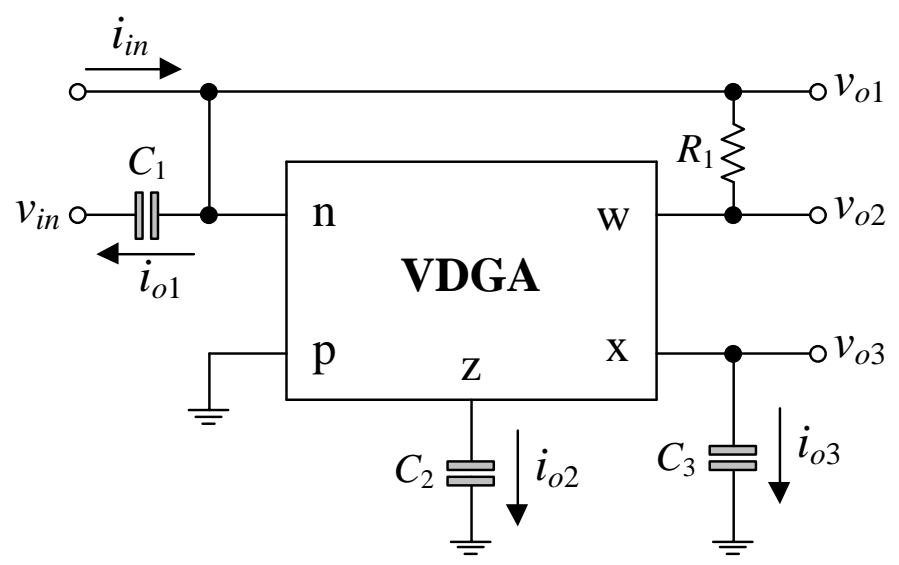

Figure 3. Proposed dual-mode multifunction filter using single VDGA.

\subsection{Voltage-mode multifunction filter}

Considering the proposed filter configuration given in Figure 3 . When the input current is removed $\left(i_{\text {in }}=\right.$ 0 ), the circuit can be considerably performed as a voltage-mode multifunction filter with single input and three output terminals. A routine circuit analysis shows that the three voltage transfer functions realized by the configuration are obtained as:

$$
\begin{aligned}
\frac{v_{o 1}}{v_{i n}} & =K_{V H P}\left[\frac{s^{2}}{D(s)}\right] \\
\frac{v_{o 2}}{v_{i n}} & =K_{V B P} \frac{\left(\frac{1}{R_{1} C_{1}}\right) s}{D(s)} \\
\text { and } \quad \frac{v_{o 3}}{v_{i n}} & =K_{V L P} \frac{\left(\frac{g_{m A} \beta}{R_{1} C_{1} C_{2}}\right)}{D(s)}
\end{aligned}
$$


where

$$
\begin{aligned}
& D(s)=s^{2}+\left(\frac{1}{R_{1} C_{1}}\right) s+\left(\frac{g_{m A} \beta}{R_{1} C_{1} C_{2}}\right) \\
& K_{V H P}=1, \quad K_{V B P}=-\frac{g_{m A} \beta R_{1} C_{1}}{C_{2}}
\end{aligned}
$$

and

$$
K_{V L P}=-\frac{g_{m C} R_{1} C_{1}}{C_{3}}
$$

The above relations express that the HP, BP, and LP voltage filtering responses are available at the terminal $v_{o 1}, v_{o 2}$ and $v_{o 3}$, with the passband gains $K_{V H P}, K_{V B P}$ and $K_{V L P}$, respectively. No component-matching choices are imposed. From the eqs. (5)-(8), the natural angular frequency $\left(\omega_{o}\right)$, and the quality factor $(Q)$ of the filter are given by, respectively:

$$
\begin{aligned}
& \omega_{o}=\sqrt{\frac{g_{m A} \beta}{R_{1} C_{1} C_{2}}} \\
& \text { and } \quad Q=\sqrt{\frac{g_{m A} \beta R_{1} C_{1}}{C_{2}}}
\end{aligned}
$$

\subsection{Current-mode multifunction filter}

In case of current-mode filter operation by connecting the input voltage of Figure 3 to ground $\left(v_{\text {in }}=0\right)$, the three current transfer functions can be readily derived as:

$$
\begin{aligned}
& \frac{i_{o 1}}{i_{i n}}=K_{I H P}\left[\frac{s^{2}}{D(s)}\right] \\
& \frac{i_{o 2}}{i_{i n}}=K_{I B P} \frac{\left(\frac{1}{R_{1} C_{1}}\right) s}{D(s)} \\
& \frac{i_{o 3}}{i_{i n}}=K_{I L P} \frac{\left(\frac{g_{m A} \beta}{R_{1} C_{1} C_{2}}\right)}{D(s)}
\end{aligned}
$$

and

where

$$
K_{I H P}=1, \quad K_{I B P}=-g_{m A} R_{1}
$$

and

$$
K_{I L P}=-g_{m C} R_{1}
$$

It can be noted from the eqs. (13)-(15) that the three transfer functions of HP, BP and LP in current-mode across explicitly available current outputs $i_{o 1}, i_{02}$ and $i_{o 3}$, respectively. In all cases, the characteristic parameters $\omega_{o}$ and $Q$ are be the same as that of eqs. (11) and (12). 


\section{Non-ideal consideration and sensitivity analysis}

For the practical consideration, the characteristic of the non-ideal VDGA can be described by the following matrix:

$$
\left[\begin{array}{c}
i_{p} \\
i_{n} \\
i_{z} \\
i_{x} \\
v_{w}
\end{array}\right]=\left[\begin{array}{cccc}
0 & 0 & 0 & 0 \\
0 & 0 & 0 & 0 \\
\alpha_{A} g_{m A} & -\alpha_{A} g_{m A} & 0 & 0 \\
0 & 0 & \alpha_{B} g_{m B} & 0 \\
0 & 0 & \delta \beta & 0
\end{array}\right]\left[\begin{array}{c}
v_{p} \\
v_{n} \\
v_{z} \\
v_{x}
\end{array}\right]
$$

In the eq. (18), $\alpha_{k}=1-\varepsilon_{k}\left(\left|\varepsilon_{k}\right|<<1\right)$ and $\delta=1-\varepsilon_{v}\left(\left|\varepsilon_{v}\right|<<1\right)$, where $\varepsilon_{k}$ and $\varepsilon_{v}$ are the tracking errors of the VDGA. Therefore, taking into consideration the non-idealities of the VDGA, the derived expressions for the non-ideal parameters $\omega_{o}$ and $Q$ of the proposed filter in Figure 3 are now given below:

$$
\omega_{o}=\sqrt{\frac{\alpha_{A} \delta g_{m A} \beta}{R_{1} C_{1} C_{2}}}
$$

and

$$
Q=\sqrt{\frac{\alpha_{A} \delta g_{m A} \beta R_{1} C_{1}}{C_{2}}}
$$

According to above considerations, the relative sensitivities of the $\omega_{o}$ and $Q$ to individual circuit components are obtained as:

$$
\begin{gathered}
S_{\alpha_{A}}^{\omega_{o}}=S_{\delta}^{\omega_{o}}=S_{g_{m A}}^{\omega_{o}}=S_{\beta}^{\omega_{o}}=0.5 \\
S_{R_{1}}^{\omega_{o}}=S_{C_{1}}^{\omega_{o}}=S_{C_{2}}^{\omega_{o}}=-0.5 \\
S_{\alpha_{A}}^{Q}=S_{\delta}^{Q}=S_{g_{m A}}^{Q}=S_{\beta}^{Q}=0.5
\end{gathered}
$$

and

$$
S_{R_{1}}^{Q}=S_{C_{1}}^{Q}=-S_{C_{2}}^{Q}=0.5
$$

It can be easily verified that all the relative $\omega_{o}$ and $Q$ sensitivities with respect to various circuit elements are equal to 0.5 in magnitude. Note that, for the absolutely stable circuit, the sensitivity values of all $\omega_{o}$ and $Q$ will be no more than unity.

\section{Performance verification}

The performance of the proposed single VDGA-based dual-mode multifunction filter in Figure 3 has been verified by PSPICE simulation results. For this purpose, the simulation is based on the use of the CMOS VDGA structure given in Figure 2, where its performance is given in Table 2 [10]. For all simulations, the capacitor values were $C_{1}=C_{2}=100 \mathrm{pF}$.

In order to design the filter with the following characteristic: $f_{o}=\omega_{o} / 2 \pi \cong 526 \mathrm{kHz}$ and $Q=1$, the circuit components were set to be: $g_{m}=g_{m k}=0.33 \mathrm{~mA} / \mathrm{V}\left(I_{B}=I_{B k}=30 \mu \mathrm{A}\right)$ and $R_{1}=3 \mathrm{k} \Omega$. The theoretical and simulation results of the HP, BP and LP responses for the proposed voltage-mode filter structure are depicted in Figure 4-6, respectively. It is, therefore, appeared that the simulation results are found to be agreed with the theoretical values, and they verify the functionality of the proposed VDGA-based multifunction filter configuration. Also, the total power consumption obtained from the simulation result is approximately 0.916 $\mathrm{mW}$. With the component values given above, the simulated transient waveforms of the BP output voltage 
$\left(v_{o 2}\right)$ with a $100-\mathrm{mV}$ peak sinusoidal input voltage $\left(v_{i n}\right)$ at the operating frequency of $526 \mathrm{kHz}$ are given in Figure 7.

Table 2. Some important parameters of CMOS VDGA in Figure 2.

\begin{tabular}{|c|c|}
\hline Parameter & Value \\
\hline Technology & TSMC $0.35-\mu \mathrm{m}$ \\
\hline Supply voltages & $\pm 1.5 \mathrm{~V}$ \\
\hline $\begin{array}{c}\text { Power consumption } \\
\left(I_{B k}=30 \mu \mathrm{A}\right)\end{array}$ & $0.747 \mathrm{~mW}$ \\
\hline $\begin{array}{c}\text { Terminal } p \text { resistance } \\
(f=1 \mathrm{kHz} \sim 100 \mathrm{MHz})\end{array}$ & $2 \mathrm{G} \Omega \sim 20 \mathrm{k} \Omega$ \\
\hline $\begin{array}{c}\text { Terminal } n \text { resistance } \\
(f=1 \mathrm{kHz} \sim 100 \mathrm{MHz})\end{array}$ & $2 \mathrm{G} \Omega \sim 20 \mathrm{k} \Omega$ \\
\hline $\begin{array}{c}\text { Terminal } z \text { resistance } \\
(f=1 \mathrm{kHz} \sim 100 \mathrm{MHz})\end{array}$ & $190 \mathrm{M} \Omega \sim 20 \mathrm{k} \Omega$ \\
\hline $\begin{array}{c}\text { Terminal } x \text { resistance } \\
(f=1 \mathrm{kHz} \sim 100 \mathrm{MHz})\end{array}$ & $920 \mathrm{k} \Omega \sim 25 \mathrm{k} \Omega$ \\
\hline $\begin{array}{c}\text { Terminal } w \text { resistance } \\
(f=1 \mathrm{kHz} \sim 100 \mathrm{MHz})\end{array}$ & $\sim 3 \mathrm{k} \Omega$ \\
\hline $\begin{array}{c}\text { DC offset voltage from } p \text { to } \\
z\end{array}$ & $1.27 \mathrm{mV}$ \\
\hline $\begin{array}{c}\text { DC offset voltage from } n \text { to } \\
z\end{array}$ & $1.27 \mathrm{mV}$ \\
\hline $\begin{array}{c}\text { DC offset voltage from } z \text { to } \\
w\end{array}$ & $0.96 \mathrm{mV}$ \\
\hline $\begin{array}{c}\text { DC offset current from } z \text { to } \\
x\end{array}$ & $1.56 \mu \mathrm{A}$ \\
\hline $\begin{array}{c}\text { Transconductance } \\
\text { bandwidth }\end{array}$ & $160 \mathrm{MHz}$ \\
\hline Voltage transfer bandwidth & $145 \mathrm{MHz}$ \\
\hline
\end{tabular}

Gain Phase

(dB) (degree)

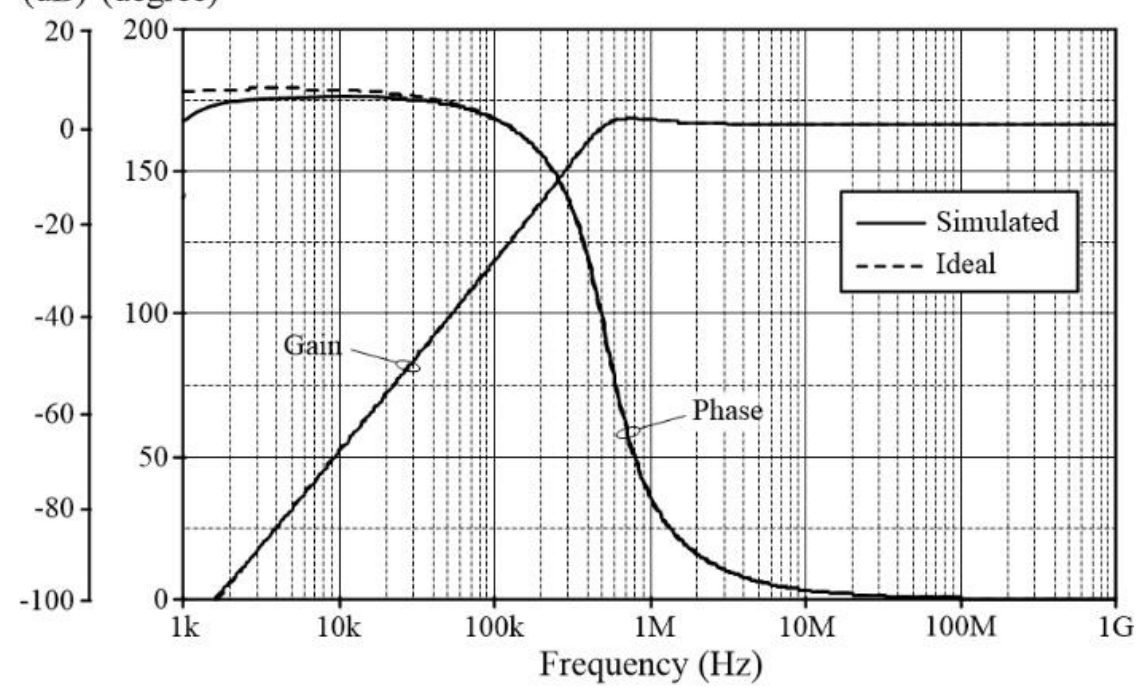

Figure 4. HP frequency characteristics of the proposed voltage-mode filter in Figure 3. 


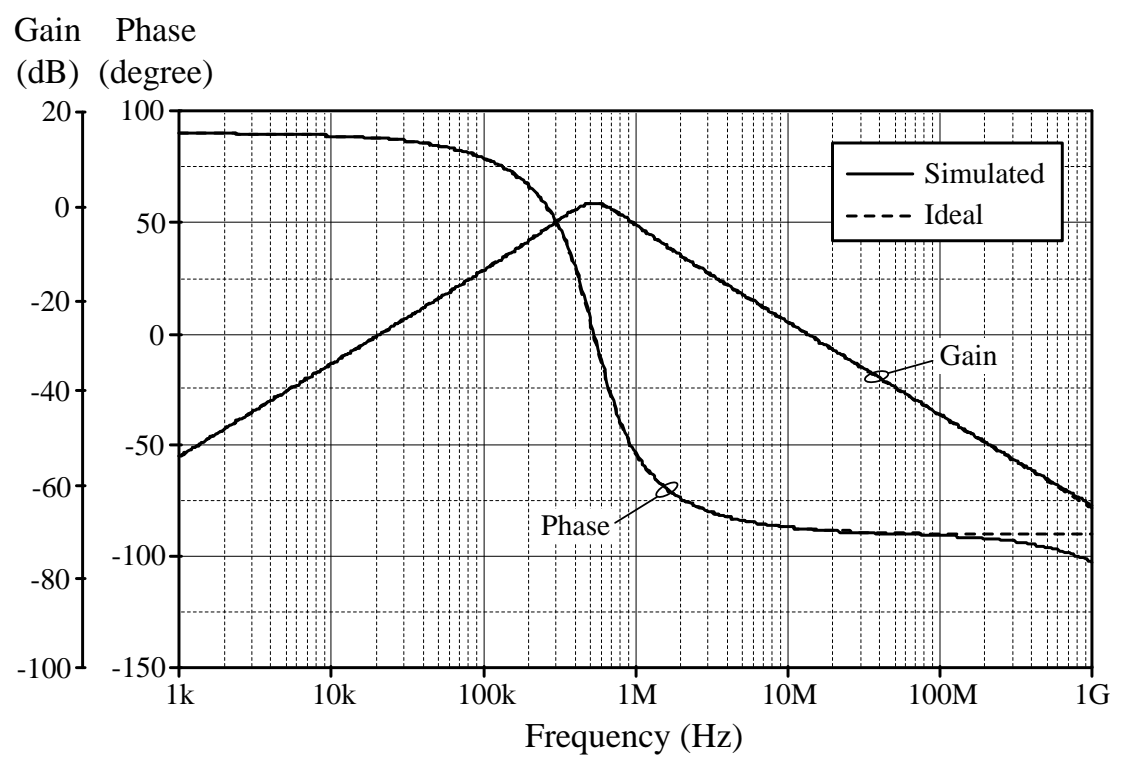

Figure 5. BP frequency characteristics of the proposed voltage-mode filter in Figure 3.

Gain Phase

(dB) (degree)

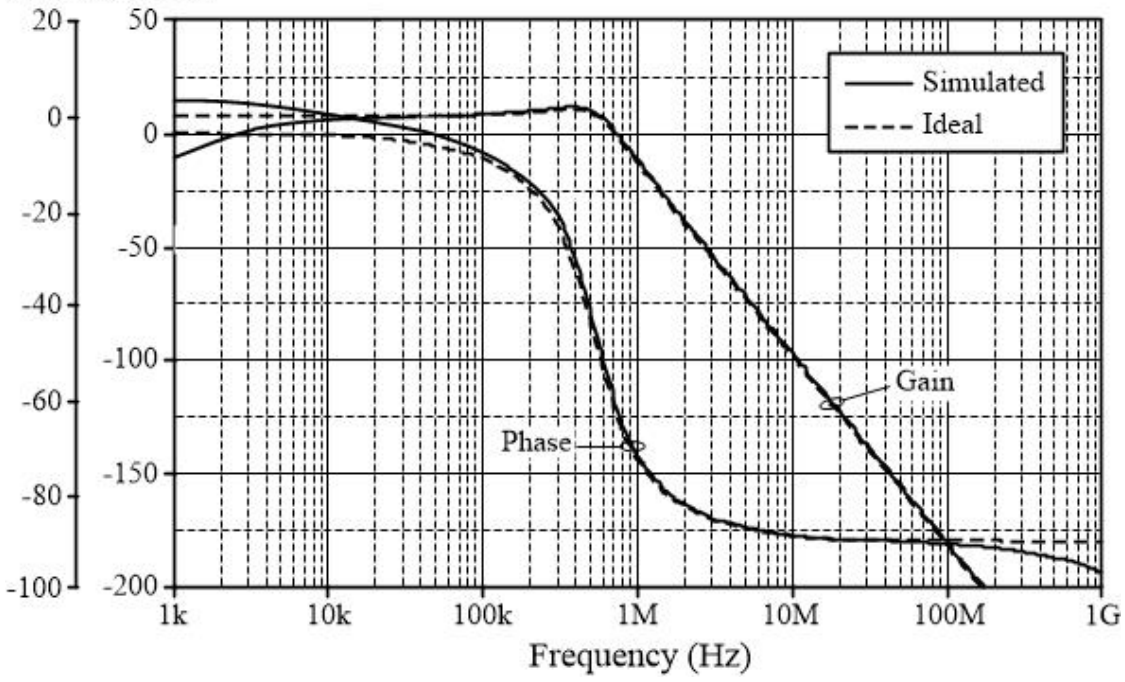

Figure 6. LP frequency characteristics of the proposed voltage-mode filter in Figure 3.

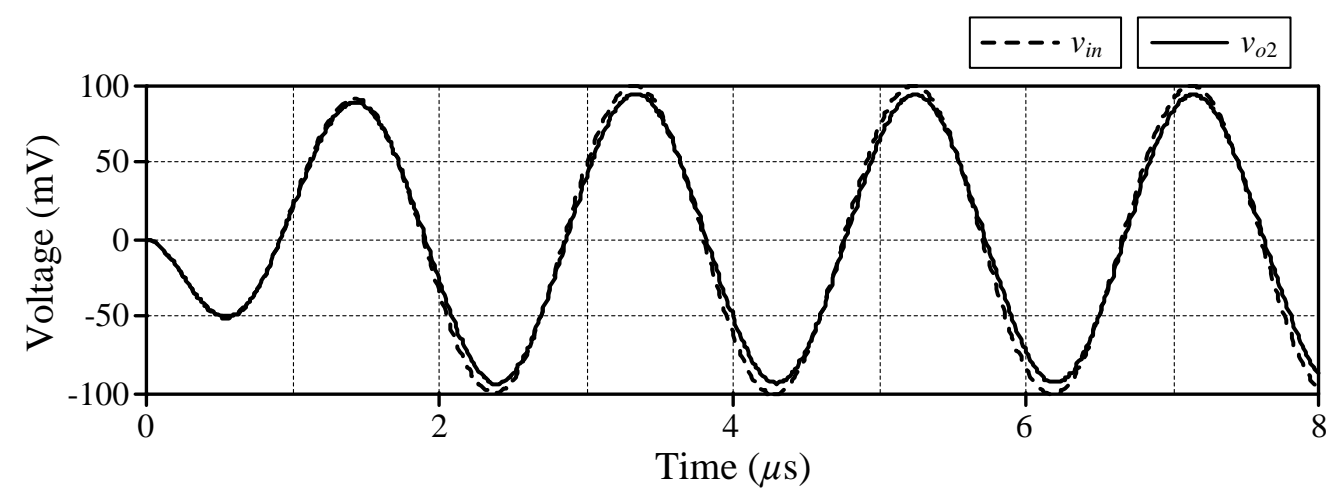

Figure 7. Simulated transient responses of the BP output voltage ( $\left.v_{o 2}\right)$. 
To observe an adjustment of $f_{o}$ with $Q$ unchanged, the simulated BP voltage responses for three different values of $I_{B}$ are shown in Figure 8. The simulation values of the bias currents and their corresponding parameters are given in Table 3. From Table 3, an independent adjustment of the $f_{o}$-value for $Q$ constant at unity can be simply achieved by keeping $g_{m}=1 / R_{1}$, and changing these values simultaneously. On the other hand, the simulated gain-frequency characteristics for the BP filter with $Q$-tuning and keeping $f_{o}$ invariant are shown in Figure 9. To achieve this, the component values for simulating the proposed voltage-mode filter of Figure 3 are listed in Table 4. For given $f_{o}$, an orthogonal electronic adjustment of $Q$ is accomplished through setting the $\left(g_{m A} \beta\right) / R_{1}$ value fixed and tuning $\beta$ only. Figure 9 demonstrates that the BP voltage responses for $Q$ $=0.5,1$ and 5 when $f_{o}$ remains constant at $526 \mathrm{kHz}$ are obtained. As evident from Figure 8 and 9 , the characteristics $\omega_{o}$ and $Q$ of the proposed single VDGA-based multifunction filter in Figure 3 can be tuned orthogonally.

Table 3. Simulation settings for orthogonal tuning of $f_{o}$ without changing $Q$.

\begin{tabular}{|c|c|c|c|c|c|}
\hline $\begin{array}{c}I_{B}=I_{B k} \\
(\mu \mathrm{A})\end{array}$ & $\begin{array}{c}g_{m}=g_{m k} \\
(\mu \mathrm{A} / \mathrm{V})\end{array}$ & $\begin{array}{c}\beta \\
\left(g_{m B} / g_{m C}\right)\end{array}$ & $\begin{array}{c}R_{1} \\
(\mathrm{k} \Omega)\end{array}$ & $\begin{array}{c}f_{o} \\
(\mathrm{kHz})\end{array}$ & $Q$ \\
\hline 10 & 191 & 1 & 5.2 & 304 & 1 \\
\hline 30 & 330 & 1 & 3 & 526 & 1 \\
\hline 70 & 505 & 1 & 2 & 803 & 1 \\
\hline
\end{tabular}

Table 4. Simulation settings for orthogonal tuning of $Q$ without changing $f_{o}$.

\begin{tabular}{|c|c|c|c|c|c|}
\hline $\begin{array}{c}I_{B A} \\
(\mu \mathrm{A})\end{array}$ & $\left(g_{m A} \beta\right) / R_{1}$ & $\begin{array}{c}\beta \\
\left(g_{m B} / g_{m C}\right)\end{array}$ & $\begin{array}{c}R_{1} \\
(\mathrm{k} \Omega)\end{array}$ & $\begin{array}{c}f_{o} \\
(\mathrm{kHz})\end{array}$ & $Q$ \\
\hline 30 & $110 \times 10^{-6}$ & 0.5 & 1.5 & 526 & 0.5 \\
\hline 30 & $110 \times 10^{-6}$ & 1 & 3 & 526 & 1 \\
\hline 30 & $110 \times 10^{-6}$ & 5 & 15 & 526 & 5 \\
\hline
\end{tabular}

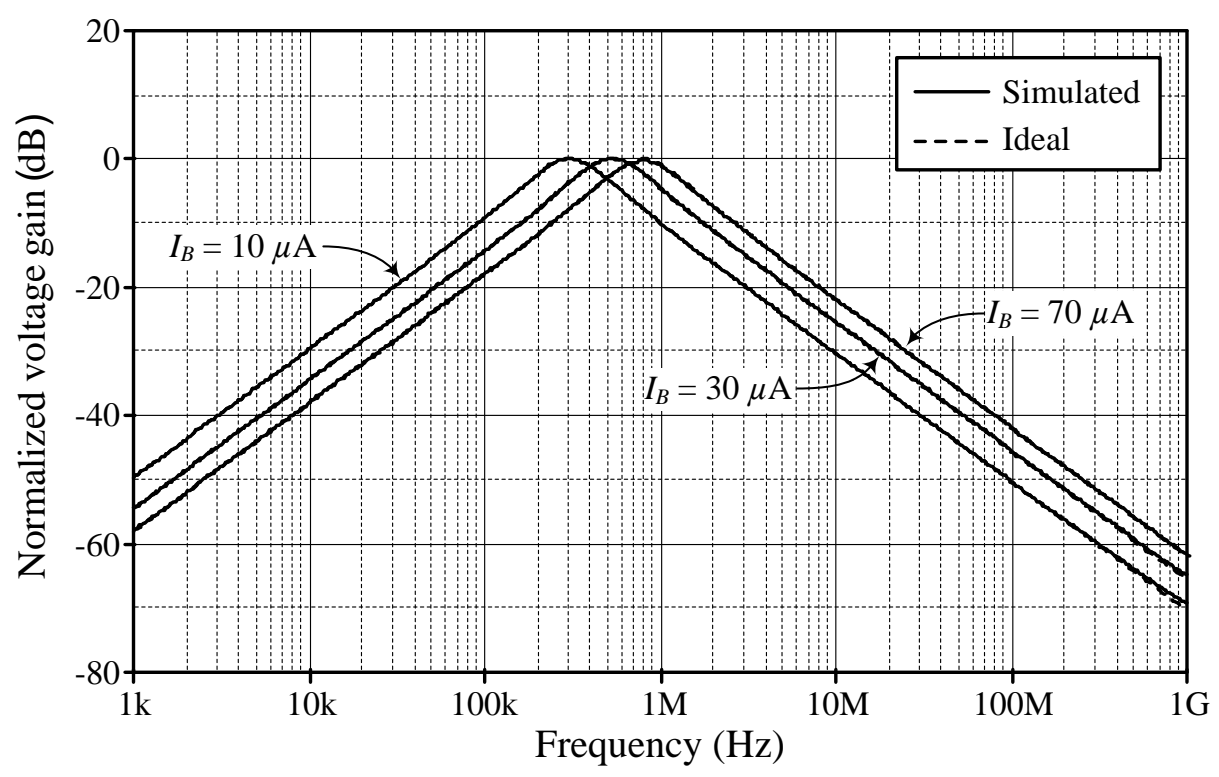

Figure 8. Simulated BP voltage responses with $f_{o}$-tuning while keeping $Q$ invariant. 


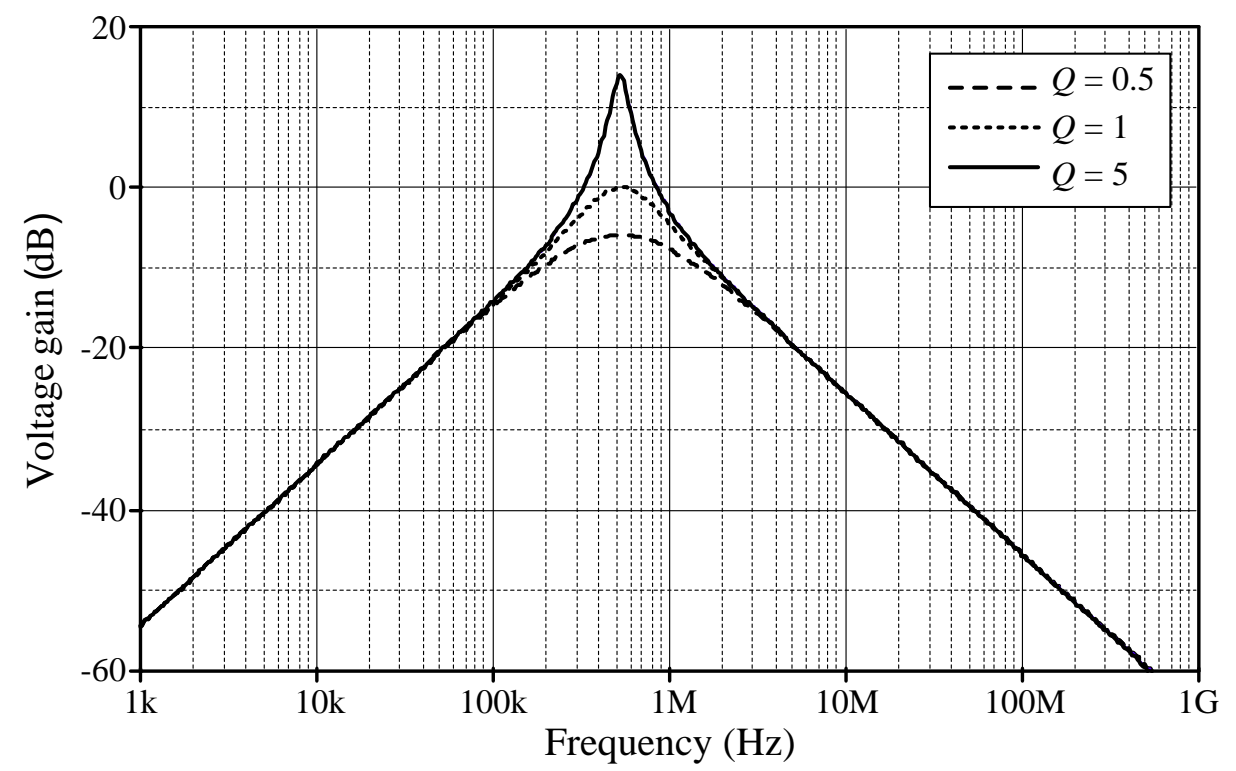

Figure 9. Simulated BP voltage responses with $Q$-tuning while keeping $f_{o}$ invariant.

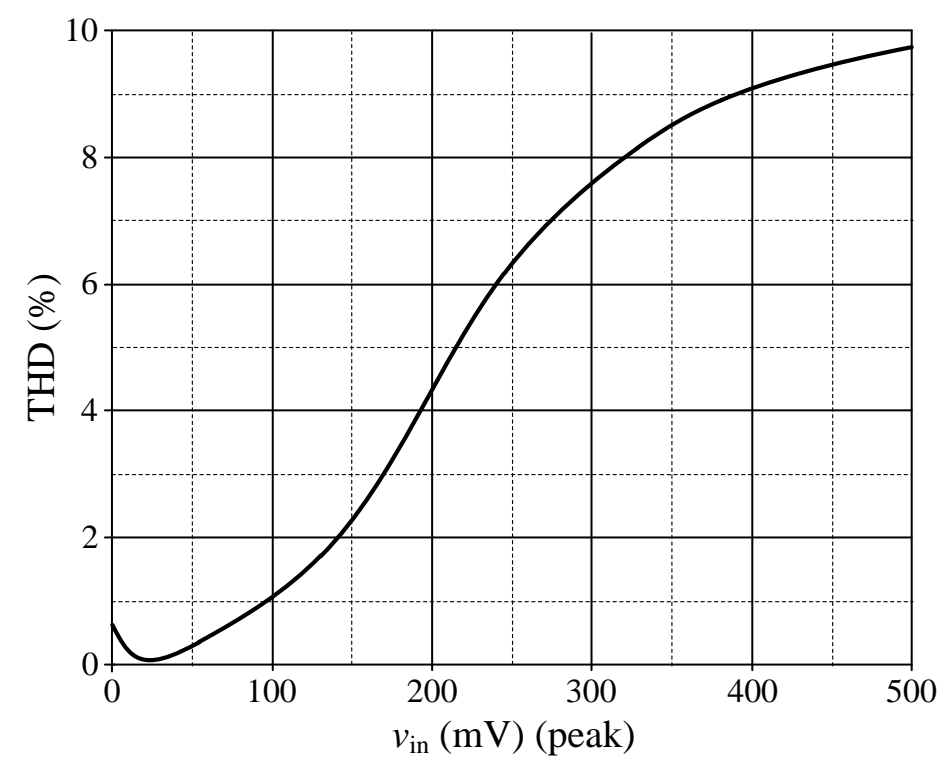

Figure 10. THD variation of the BP output against the input signal amplitude.

To further judge the large signal performance of the proposed voltage-mode filter in Figure 3, the total harmonic distortion (THD) of the BP output has been investigated by injecting a $526-\mathrm{kHz}$ sinusoidal input voltage signal. The THD values on this input signal amplitude at the BP filter are plotted in Figure 10. It can be observed that, for the input current amplitude up to $500 \mathrm{mV}$ (peak), the THD value remains within the level of $10 \%$.

Also, statistical analysis of the proposed circuit has been studied by performing Monte-Carlo simulations. Using Monte-Carlo analysis with 100 runs, the simulation results of BP filter response for 5\% Gaussian deviation in the VDGA transconductance values $\left(g_{m \mathrm{k}}\right)$ are given in Figure 11, where the standard deviation of the $f_{o}$ was found as $3.10 \mathrm{kHz}$. An additional simulation for BP gain-frequency response is given in Figure 12 to demonstrate the change in the $f_{o}$-value with operating temperature variations. From these plots, it is observed that the $f_{o}$-value of the filter is affected by $-6.84 \%$ to $+4.56 \%$ for the temperature discretely swept from $0^{\circ} \mathrm{C}$ to $100^{\circ} \mathrm{C}$ in $10^{\circ} \mathrm{C}$ steps. 
(a)
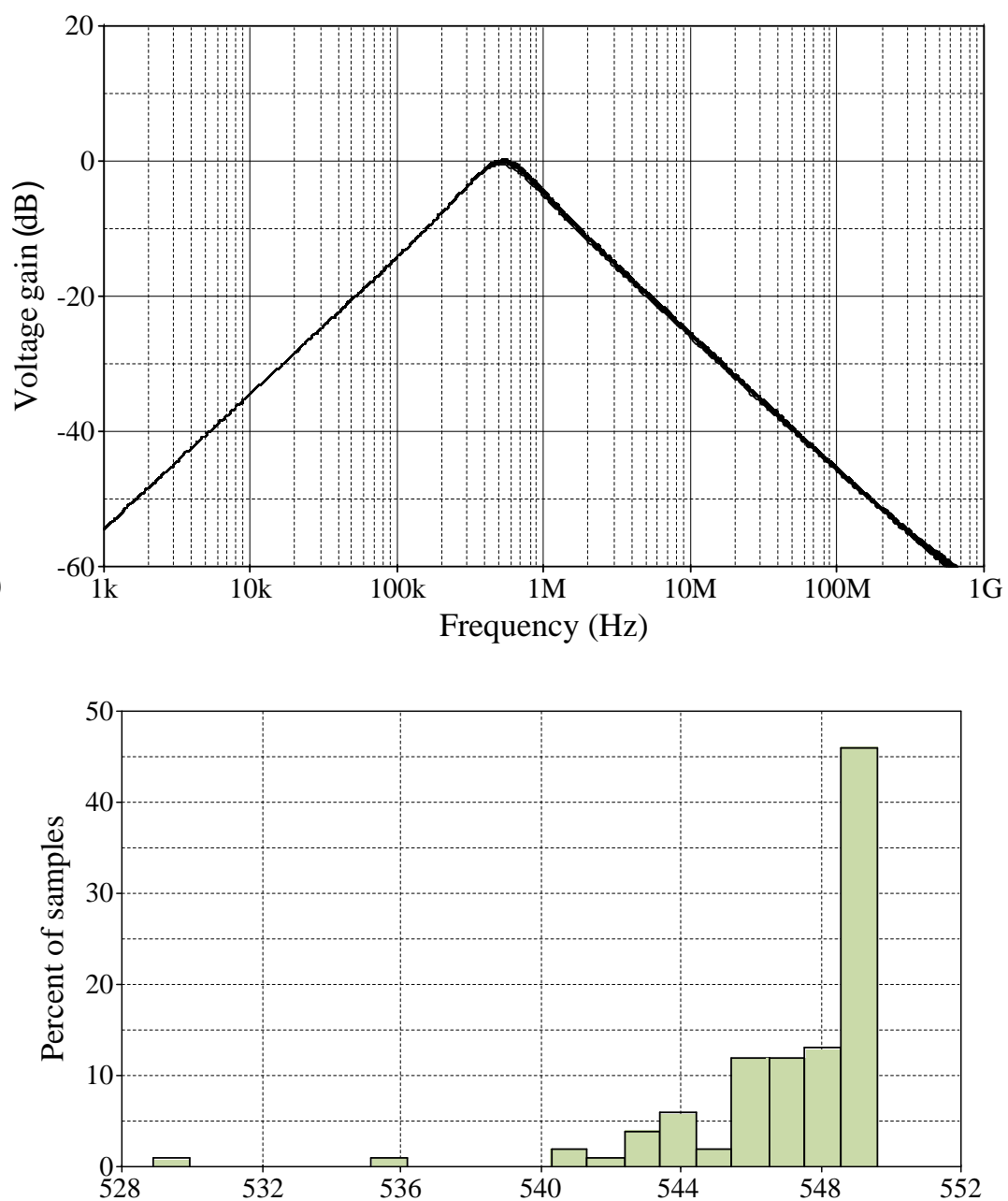

(a)

Frequency $(\mathrm{kHz})$

\begin{tabular}{|llllll|}
\hline $\mathrm{n}$ samples & $=100$ & sigma & $=3101.93$ & median & $=548195$ \\
$\mathrm{n}$ divisions & $=20$ & minimum & $=528912$ & 90th \%ile & $=549533$ \\
mean & $=547156$ & 10th \%ile & $=543526$ & maximum & $=549601$
\end{tabular}

Figure 11. Monte-Carlo analysis results for $f_{o}$ of BP response. (a) frequency domain (b) derived histogram

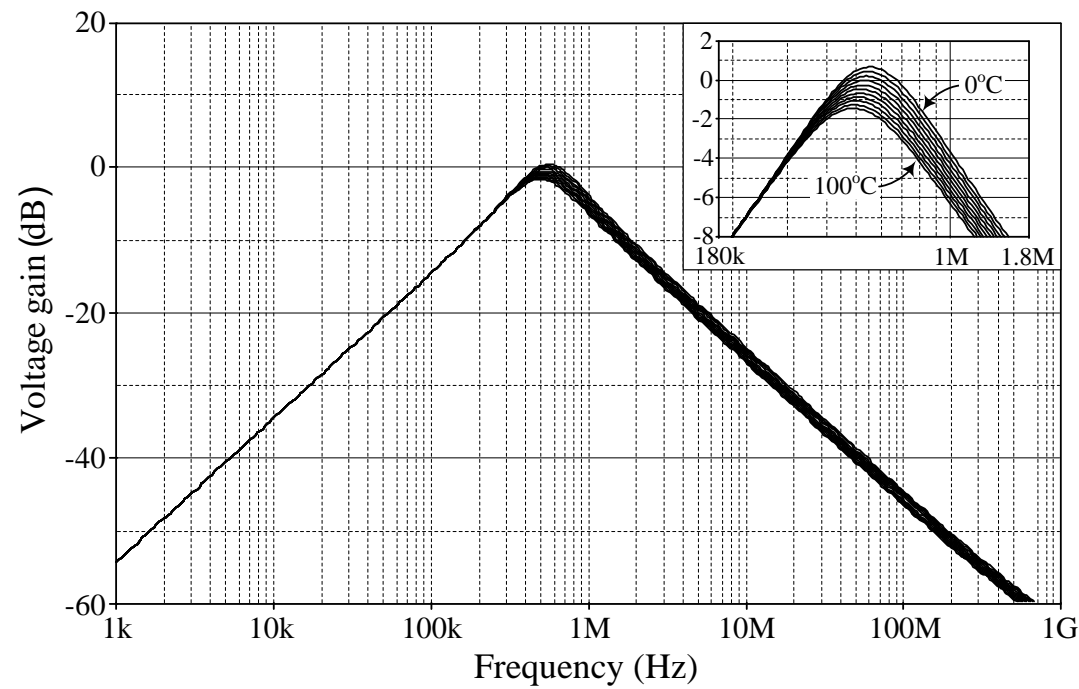

Figure 12. Simulated BP frequency characteristics with different operating temperatures. 
Another set of simulations has also been carried out to evaluate the performance of the proposed currentmode multifunction filter. Figure 13 shows the ideal and simulated HP, BP and LP filtering current responses by setting the values of $g_{m}=g_{m k}=0.33 \mathrm{~mA} / \mathrm{V}\left(I_{B}=I_{B k}=30 \mu \mathrm{A}\right)$ and $R_{1}=3 \mathrm{k} \Omega$. This setting results in the current-mode filter with $f_{o}=526 \mathrm{kHz}$ and $Q=1$. In addition, the simulated transient response of the BP output current $\left(i_{o 2}\right)$ is illustrated in Figure 14, where the 526-kHz sinusoidal input current $\left(i_{i n}\right)$ with amplitude of 80 $\mu \mathrm{A}$ peak is injected to the filter of Figure 3 .

\section{Conclusion}

In summary, a compact configuration for realizing dual-mode multifunction filter with a single input and triple outputs consisting of the single VDGA active component and four passive components has been described. The circuit can work in either voltage-mode or current-mode filter, and can realize three standard biquadratic filter functions, namely highpass, bandpass and lowpass, simultaneously from the same topology. Its $\omega_{o}$ and $Q$ parameters are orthogonally adjustable. No requirements to define component-matching choices are imposed. Non-ideal consideration and component sensitivity analysis are also discussed in detail. In both operation modes, a good correspondence between theoretical values and those obtained from PSPICE simulation results using TSMC $0.25-\mu \mathrm{m}$ CMOS technology has been achieved.

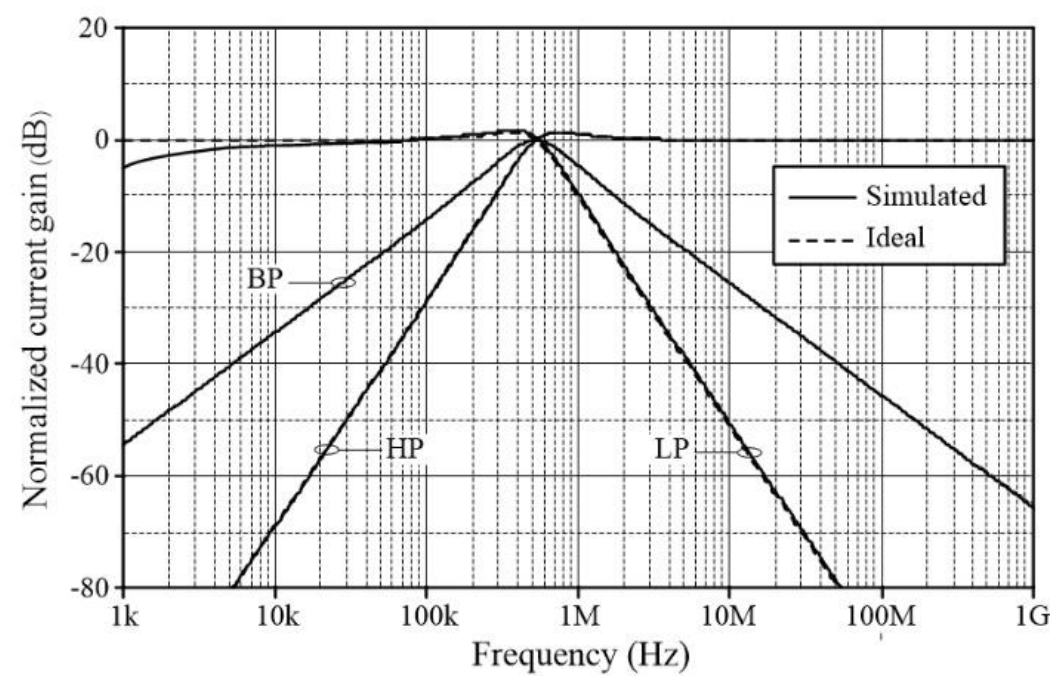

Figure 13. HP, BP and LP frequency characteristics of the proposed current-mode filter in Figure 3.

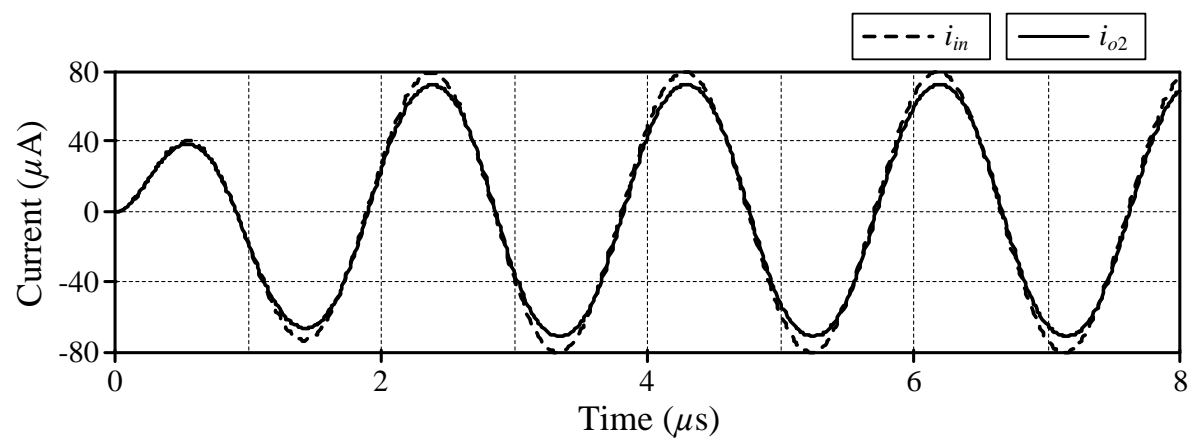

Figure 14. Simulated transient responses of the BP output current $\left(i_{o 2}\right)$.

\section{Acknowledgements}

This work was supported by King Mongkut's Institute of Technology Ladkrabang Research Fund [grant number KREF046213]. The partial support by a grant from the Institute of Research and Development Rajamangala University of Technology Isan, and Faculty of Engineering, Rajamangala University of Technology Isan, Khonkaen Campus are also gratefully acknowledged. 


\section{References}

[1] Biolek, D., Senani, R., Biolkova, V., Kolka, Z.: Active elements for analog signal processing: classification, review, and new proposals, Radioengineering, 17 (2008), 4, 15-32.

[2] Yesil, A., Kacar, F., Kuntman, H.: New simple CMOS realization of voltage differencing transconductance amplifier and its RF filter application, Radioengineering, 20 (2011), 3, 632-637.

[3] Satansup, J., Pukkalanun, T., Tangsrirat, W.: Electronically tunable single-input five-output voltage-mode universal filter using VDTAs and grounded passive elements, Circuits, Systems and Signal Processing, 32 (2013), 3, 945-957.

[4] Sotner, R., Jerabek, J., Prokop, R., Kledrowetz, V.: Simple CMOS voltage differencing current conveyorbased electronically tunable quadrature oscillator, Electronics Letters, 52 (2016), 12, 1016-1018.

[5] Kacar, F., Yesil, A., Noori, A.: New CMOS realization of voltage differencing buffered amplifier and its biquad filter applications, Radioengineering, 21 (2012), 1, 333-339.

[6] Tangsrirat, W.: Actively floating lossy inductance simulators using voltage differencing buffered amplifiers, IETE Journal of Research, 2018, doi: 10.1080/03772063.2018.1433082.

[7] Sotner, R., Jerabek, J., Herencsar, N.: Voltage differencing buffered/inverted amplifiers and their applications for signal generation, Radioengineering, 22 (2013), 2, 490-504.

[8] Pushkar, K. L., Bhaskar, D. R., Prasad, D.: Voltage-mode universal biquad filter configuration using a single VDIBA, Circuits, Systems and Signal Processing, 33 (2014), 1, 275-285.

[9] Tangsrirat, W.: Synthetic grounded lossy inductance simulators using single VDIBA, IETE Journal of Research, 63 (2017), 1, 134-141.

[10] Satansup, J., Tangsrirat, W.: CMOS realization of voltage differencing gain amplifier (VDGA) and its application to biquad filter, Indian Journal of Engineering \& Material Sciences, 20 (2013), 6, 457-464.

[11] Channumsin, O., Tangsrirat, W.: Compact electronically tunable quadrature oscillator using single voltage differencing gain amplifier (VDGA) and all grounded passive elements, Turkish Journal of Electrical Engineering \& Computer Sciences, 25 (2017), 4, 2686-2695.

[12] Channumsin, O., Tangsrirat, W.: Voltage differencing gain amplifier-based sinusoidal quadrature oscillator using only two grounded capacitors, Recent Advances in Electrical \& Electronic Engineering, 2019, doi : 10.2174/2352096512666181219121941.

[13] Satansup, J., Tangsrirat, W., Surakampontorn, W.: Voltage differencing gain amplifier-based quadrature oscillator employing all grounded passive elements, Proceedings of The 18th International Symposium on Communications and Information Technologies (ISCIT 2018), Bangkok, Thailand, 2018, 251-254.

[14] Satansup, J., Tangsrirat, W.: Single VDGA-based first-order allpass filter with electronically controllable passband gain, Proceedings of 2015 The 7th International Conference on Information Technology and Electrical Engineering (ICITEE-2015), Chiang Mai, Thailand, 2015, 106-109.

[15] Taskiran, Z. G. C., Sedef, H., Anday, F.: Voltage differencing gain amplifier-based Nth-order low-pass voltage-mode filter, Journal of Circuits, Systems and Computers, 27 (2018), 6, 1850089.

[16] Channumsin, O., Tangsrirat, W.: Dual-mode multifunction filter using VDGAs, Proceedings of 15th International Conference on Electrical Engineering/Electronics, Computer, Telecommunications and Information Technology (ECTI-CON 2018), Chiang Rai, Thailand, 2018, 86-89.

[17] Horng, J. W., Lay, J. R., Chang, C. W., Lee, M. H.: High input impedance voltage-mode multifunction filters using plus-type CCIIs, Electronics Letters, 33 (1997), 6, 472-473.

[18] Horng, J. W., Lee, M. H.: High input impedance voltage-mode lowpass, bandpass and highpass filter using current-feedback amplifiers, Electronics Letters, 33 (1997), 11, 947-948.

[19] Chang, C. M., Lee, M. J.: Voltage-mode multifunction filter with single input and three outputs using two component current conveyors, IEEE Trans.Circuits Syst.-I: Fundamental Theory Applications, 46 (1999), $11,1364-1365$.

[20] Horng, J. W., Chiu, W. Y., Wei, H. Y.: Voltage-mode highpass, bandpass and lowpass filters using two DDCCs, International Journal of Electronics, 91 (2004), 8, 461-464.

[21] Chen, H. P.: Universal voltage-mode filter using only plus-type DDCCs, Analog Integrated Circuits and Signal Processing, 50 (2007), 2, 137-139.

[22] Tangsrirat, W., Channumsin, O.: High input impedance voltage-mode multifunction filters using a single DDCCTA and grounded passive elements, Radioengineering, 20 (2011), 4, 905-910. 
[23] Ibrahim, M. A., Minaei, S., Kuntman, H.: A 22.5 MHz current-mode KHN-biquad using differential voltage current conveyor and grounded passive element, International Journal of Electronics and Communications (AEU), 59 (2005), 5, 311-318.

[24] Keskin, A. U., Cam, U.: Insensitive high-output impedance minimum configuration SITO-type currentmode biquad dual-output current conveyors and grounded passive components, International Journal of Electronics and Communications (AEU), 61 (2007), 5, 341-344.

[25] Prasad, D., Bhaskar, D. R., Singh, A. K.: Universal current-mode biquad filter using dual output current differencing transconductance amplifier, International Journal of Electronics and Communications (AEU), 63 (2009), 497-501.

[26] Minaei, S., Turkoz, S.: New current-mode current-controlled universal filter with single input and three outputs, International Journal of Electronics, 88 (2001), 3, 333-337.

[27] Prasad, D., Bhaskar, D. R., Srivastava, M.: Universal current-mode biquad filter using a VDTA, Circuits and Systems, 4 (2013), 1, 32-36.

[28] Arbel, A. F., Goldminz, L.: Output stage for current-mode feedback amplifiers, theory and applications, Analog Integrated Circuits and Signal Processing, 2 (1992), 3, 243-255.

[29] Pal, K., Singh, R.: Inductorless current conveyor all-pass filter using grounded capacitors, Electronics Letters, 18 (1982), 1, 47.

[30] Baker, R. J., Li, H. W., Boyce, D. E.: CMOS Circuit Design, Layout and Simulation, IEEE Press, New York, 1998.

[31] Wang, Z.: Novel electronically-controlled floating resistors using MOS transistors operating insaturation, Elelctronics Letters, 27 (1991), 2, 188-189. 